\title{
Memória viva das ciências da comunicação
}

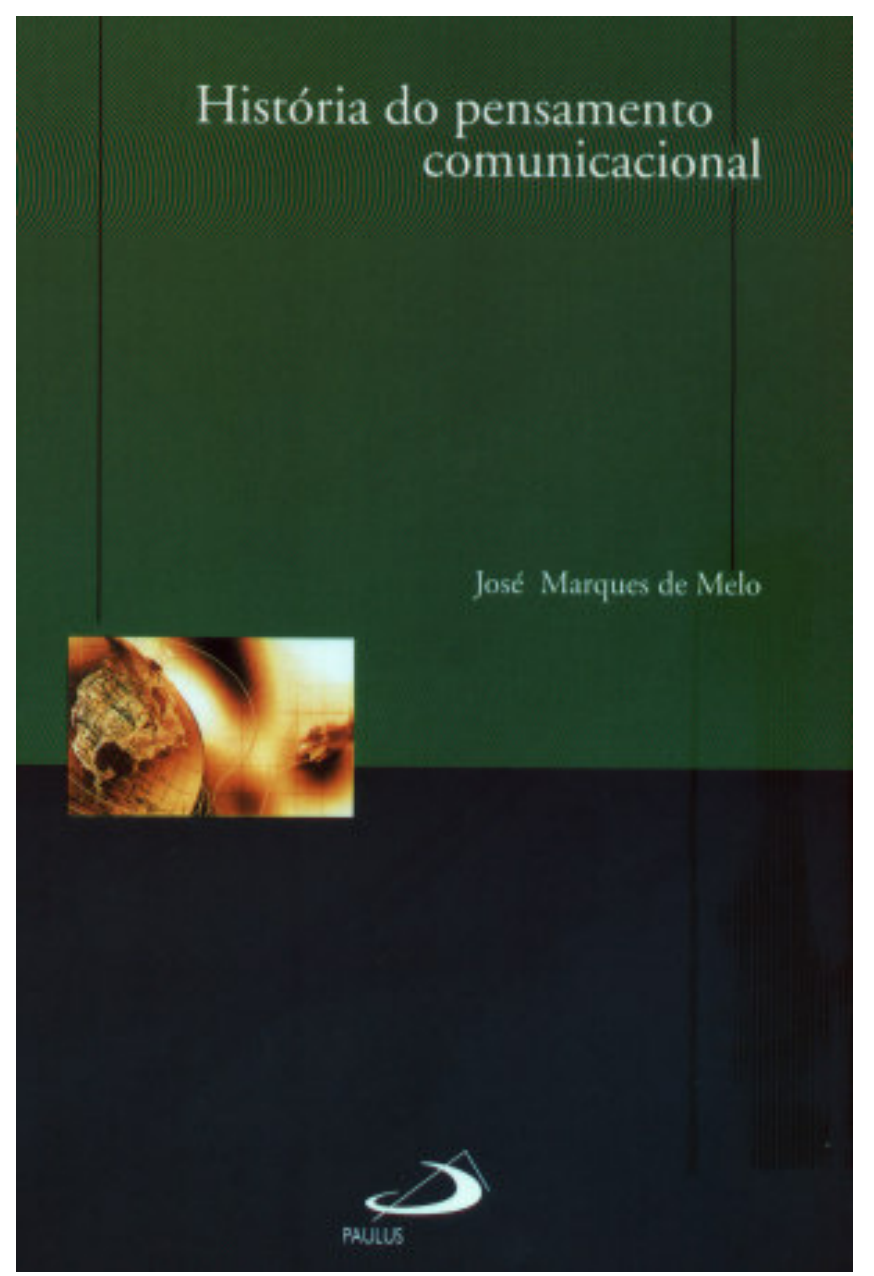

MARQUES DE MELO, José. História do pensamento comunicacional: cenários e personagens. 2. ed. São Paulo: Paulus, 2007. 373 p.

\section{Francisco de Assis}

Mestrando da Universidade Metodista de São Paulo UMESP/SP/BR francisco-nupec@uol.com.br
O campo científico da comunicação talvez seja a arena mais controversa entre as ramificações da ciência. Refutado por diferentes níveis hierárquicos dentro do sistema formal de produção acadêmica, a área teve, em várias ocasiões e especialmente no Brasil, sua própria legitimidade colocada à prova. "Afinal, comunicação é ciência?", questionam os apocalípticos (e até mesmo alguns integrados, para citar Umberto Eco), pondo em dúvida o real valor do saber gerado nesse eixo. Mas algo ninguém pode negar: há séculos, intelectuais do mundo todo têm se dedicado a refletir sobre os fenômenos comunicacionais, deixando, como legado, obras testamentais que buscam respostas para um sem-número de dúvidas, as quais, mesmo com romper de décadas a fio, permanecem relevantes. E esse conhecimento acumulado só ganha força na Academia quando não se perde na poeira do tempo e torna-se fonte referencial para novos estudos a respeito do mesmo universo.

Por essas razões, têm merecido destaque as iniciativas que visam atualizar, constantemente, tal panorama evolutivo, como é o caso do livro História do pensamento comunicacional: cenários e personagens, que ganhou uma segunda edição recentemente. Em suas páginas, José Marques de Melo esboça um amplo cronograma do pensamento ocidental sobre a comunicação, buscando raízes no século $3^{\circ}$ a.C., com a recuperação das idéias de Aristóteles; passando por outros momentos significativos, todos transcorridos no continente europeu; até identificar bases mais sólidas no campo acadêmico, jogando luzes sobre os Estados Unidos, já no século 20.

Antes de mais nada, é importante dizer que a obra sintetiza um esforço de décadas do autor, que tem reconhecida atuação no resgate da memória das ciências da comunicação, sempre buscando equilibrar as reflexões em torno das matrizes hegemônicas (leia-se: européias e norte-americanas) com as novas correntes, especialmente a latino-americana. É ao assumir esse papel de "vigia" e "propulsor" do pensamento comunicacional como certa vez definiu Luis Ramiro Beltrán -, que Marques de Melo, professor emérito da Escola de Comunicações e Artes da Universidade de São Paulo (ECA-USP) e diretor-titular da Cátedra Unesco/Metodista de Comunicação para o Desenvolvimento Regional, tem guiado seus trabalhos, deixando sistematizado, como contribuição às novas gerações, aquilo que de mais precioso pode existir em uma sociedade: sua história.

O volume é dividido de forma didática, o que pode muito bem auxiliar os jovens pesquisadores da área a se introduzirem no assunto com certa tranqüilidade. Como seu próprio subtítulo indica, a separação é feita em duas partes, sendo a primeira destinada aos "cenários" e, a segunda, aos "personagens", demonstrando a valorização não somente das idéias relacionadas a algum movi- 
mento - como, por exemplo, a teoria crítica, sempre vinculada à Escola de Frankfurt -, mas também dos mentores que deixaram suas marcas na trajetória ali retratada.

Seguindo por um caminho lógico, o capítulo inicial propõe uma reflexão em torno das configurações do campo comunicacional, de sua origem, da formação de sua identidade e da própria natureza do conhecimento gerado a partir dos fenômenos midiáticos, os quais se constituem como verdadeiros enigmas para a comunidade científica, ou melhor, os quais se travestem de esfinge, pronta para "devorar" aqueles que não que a decifrarem (mas isso apenas para lembrar outras percepções do autor, tracejadas em obras também editadas há poucos anos).

Puxando pelo fio inicial, é bom notar que, após breve visita ao "berço" do pensamento comunicacional, Marques de Melo passa a dar ênfase a cenários bem mais próximos da realidade nacional: num primeiro momento, articula as idéias em torno da Escola Latino-Americana de Comunicação (Elacom), sinalizando pontos de ação e reação dessa perspectiva continental; posteriormente, realça o percurso luso-brasileiro, ao apontar para a evolução e a interface das idéias geradas em Portugal, no Brasil e em outros países lusófonos. Sempre com destaque ao papel das entidades representativas, organizadas pela sociedade civil, tais como a Sociedade Brasileira de Estudos Interdisciplinares da Comunicação (Intercom), a Asociación Latinoamericana de Investigadores de la Comunicación (Alaic) e a Federação Lusófona de Ciências da Comunicação (Lusocom).

No que diz respeito aos personagens, há uma inversão na ordem de representatividade, se pensada numa perspectiva mundial. O primeiro item da seção é voltado aos grupos brasileiros de pesquisa comunicacional, especificamente os das regiões centro-oeste e gaúcha, bem como o de São Bernardo, o qual representa o contingente de professores e alunos do Programa de Pós-Graduação em Comunicação Social da Universidade Metodista de São Paulo, que desde o final da década de 1970 oferece contribuições ao campo (desde 1978, com sua implantação; e desde 1979, quando foi criada a revista Comunicação \& Sociedade, periódico mais antigo da área ainda em circulação); com relação aos outros dois grupos, escreve o autor a respeito de suas formações e tendências.

O segundo momento do tópico personagens é voltado para quatro brasileiros de vanguarda: Frei Caneca e Costa Rego (precursores da teoria e do ensino da comunicação no país, respectivamente), Carlos Rizzini e Luiz Beltrão (pioneiros dos estudos midiáticos e das ciências da comunicação, respectivamente). Os perfis dão conta, muito embora de maneira sucinta, de rever as sementes plantadas por cada um deles, levando a uma visualização do conhecimento construído em tempos remotos. Por fim, ganham destaque os primeiros pensadores do continente americano: Richard Nixon e Elihu Katz (Estados Unidos), Luiz Ramiro Beltrán e Jesus Martín Barbero (América Latina).
Aspecto que merece ser destacado é que o livro reúne artigos escritos em diferentes épocas, geralmente elaborados para conferências e demais eventos acadêmicos, mas todos revelam uniformidade textual e, mais do que isso, complementação de informações e de idéias. É finalizado, ainda, com breve perfil intelectual do autor, o qual narra as principais etapas de sua trajetória acadêmica.

História do pensamento comunicacional: cenários e personagens é, de fato, um livro sempre atual. Rico em referências das mais variadas naturezas, capazes de orientar múltiplos vieses de trabalho, oferece dados precisos sobre a comunicação. Além disso, cumpre função essencial nesse segmento: a de manter viva e atualizada a memória dessa(s) ciência(s) wamecos 